\title{
Optimization Model of Cattle Husbandry for Rural Household in Cambodia
}

\author{
Siek Darith, Shiwei Xu*, Wen Yu, Ahmed Abdul-Gafar \\ Agricultural Information Institute, Chinese Academy of Agricultural Sciences, Beijing, China \\ Email: "xushiwei@caas.cn
}

Received 2 February 2016; accepted 23 April 2016; published 30 April 2016

\begin{abstract}
Cambodia is one of the Southeast Asia. With the agricultural market integration, Cambodia rural household is adjusting livestock structure naturally. In order to provide suitable support for agriculture policy, the authors conducted a survey on 204 rural household in Cambodia. This article uses the optimization model, considering rural labor, cattle size, and animal disease risk, to analyze and get optimum result range. The result shows that the more off-farm job opportunity, suitable cattle feed structure, and investment on public health for cattle, the household income in rural Cambodia will increase.
\end{abstract}

\section{Keywords}

Cattle, Income, Optimization Model, Policy, Cambodia

\section{Introduction}

Cambodia is an agrarian country with its economic foundation largely depending on agricultural sector in which about $80 \%$ of the population living in rural areas and the majority of them making their livelihood in agriculture (MAFF, 2015) [1]. Given the contribution of agriculture to the national GDP, more attentions are being geared towards Cambodia agriculture currently. The livestock farming has been serves as one of the major source of income and capital accumulation for farming households (Maclean, 1998) [2]. Cattle in Cambodia are the domestic livestock mainly reared for draft-and-transport power, breeding, and selling. In 2012, around 3.4 million cattle were mostly raised by small-scale farmers, fed using native grasses and crop residues (MAFF, 2013) [3]. Rice straw and fresh grass is the common feed use by local farmers including free land grazing and cut-andcarry to the pen. Pen et al. (2010) [4] stated that in the early wet season, cattle feed majorly include grazing and cut-and-carry with more importance to the latter as there are more land available for collecting grasses. Stür and Horne (1991 and 2001) [5] [6] suggested that feeding the cattle with the native grasses and crop residues was becoming limited as the number of animal increases which can lead to reduction the animal productivities. In addition, most Cambodian farmers have traditionally raised their animals with shortage knowledge about the proper animal husbandry management, resulting low productivity. Hypothetically, traditionally raising habits are can be a constraint to the cattle productivity. Local farmers can improve their productivity if there is an efficient

\footnotetext{
"Corresponding author.
} 
and effective system that can minimal input and cost.

Cattle production has been encountering setbacks since 2009. The cattle production has declined to about 24.5\% from 2009 to 2014 (FAO, 2016) [7]. Scholars such as Hun (2014) [8] stipulated that the decline came as a result of the shift of farmers' resources rearing of other livestock such as pig, poultry. These change are caused by the fear of limited in the feed, spread of diseases, continues increase in labor cost. Therefore, this study aim at analyzing optimization model of cattle production to small-scale in rural in Cambodia. This study is expected to give a guideline model to set up appropriate strategies for future developments of the cattle production in Cambodia and also expected to reveal main optimum result range and feed structure on cattle production as a whole.

\section{Data and Its Description}

\section{Data Resource and Description}

The study conducted it survey in Battambang province of Cambodia under 6 districts, 12 communes and 18 villages. Standard questionnaires were administered by face to face interviews with 204 households. The sampling method purposely targets only the farmers rearing animal. All the data were collected by the authors and some student from AII-CAAS, UME and RUA. Battambang is well known for her vast area and one of the largest rice producers in Cambodia and thus is a great source for animal feed. 204 farmer households were interview in which 197 households rear cattle.

Moreover, the highest average cattle number is in RatannakMondol district about 9.7 head per household followed by Banan, Sangkae, and Thma koul with 7.9, 7.6 and 7.0 head/household respectively. The average family number is about 4 to 5 person consisting of 3 to 4 laborer per households. The off-farm labor is household labors that have other jobs outside the farm. Very few members of the household works outside, the highest average is seen in Thma koul district 0.7 per household followed by Banan and Moung Russei district roughly 0.4 person, and the lowest outside occupation household member (0.1) is seen in Aek Phnum district. Table $\mathbf{1}$ also shows the average of labor ratio for cattle as approximately 0.4 in all the districts.

Regarding to Cambodia situation and the result showing in Table 2, Most of the farmers rearing cattle also cultivate rice thus the cost of rice straw is minimal to just the cost of transporting it from the field to the animal farm. Similar situation goes with the cost of cut and carry grass although they sometimes buy from other farmers which makes the price above a little higher than rice straw. In other cases, farmers with little or no labor force employ someone to provide a $30 \mathrm{~kg}$ of fresh grass at the cost of about 10,000 riel (about 2.5 dollars). On average, about 2.7 dollars is spent on healthcare including vaccination, de-worming and other treatments. The highest healthcare cost experienced by farmers is the treatment on sick cattle but for vaccination, the Ministry of Agriculture, Forestry and Fisheries provides free or cheap vaccination. Farmers on average spend about 5.23 dollars/head/month on labor. Other costs include the rent of land and miscellaneous cost. In the above table also presents the current prices of ox, cow and calves, the income accrued from jobs outside the farm and earnings from other agricultural production.

Table 1. Information of respondents in six district.

\begin{tabular}{|c|c|c|c|c|c|c|c|c|c|}
\hline $\mathrm{N}^{\circ}$ & Districts & $\begin{array}{l}\text { Household } \\
\text { sample }\end{array}$ & $\begin{array}{l}\text { Household } \\
\text { with cattle }\end{array}$ & $\begin{array}{c}\text { Average } \\
\text { cattle per } \\
\text { household }\end{array}$ & $\begin{array}{c}\text { Cattle } \\
\text { death rate }\end{array}$ & $\begin{array}{c}\text { Average } \\
\text { family } \\
\text { number }\end{array}$ & $\begin{array}{l}\text { Labor per } \\
\text { household }\end{array}$ & $\begin{array}{c}\text { Labor } \\
\text { off-farm } \\
\text { job }\end{array}$ & $\begin{array}{l}\text { Labor ratio } \\
\text { for livestock }\end{array}$ \\
\hline 1 & Aek Phnum & 39 & 39 & 5.1 & $3.0 \%$ & 4.7 & 2.8 & 0.1 & 0.37 \\
\hline 2 & Banan & 31 & 30 & 7.9 & $1.9 \%$ & 4.5 & 3.2 & 0.4 & 0.40 \\
\hline 3 & Moung Ruessei & 37 & 37 & 6.3 & $2.5 \%$ & 4.2 & 3.2 & 0.4 & 0.40 \\
\hline 4 & Ratanak Mondol & 20 & 20 & 9.7 & $1.0 \%$ & 4.5 & 3.2 & 0.3 & 0.43 \\
\hline 5 & Sangkae & 47 & 44 & 7.6 & $3.5 \%$ & 4.5 & 2.6 & 0.2 & 0.39 \\
\hline \multirow[t]{2}{*}{6} & Thma Koul & 30 & 27 & 7.0 & $1.5 \%$ & 4.9 & 3.6 & 0.7 & 0.36 \\
\hline & Total & 204 & 197 & 7.1 & $2.4 \%$ & 4.5 & 3.0 & 0.3 & 0.39 \\
\hline
\end{tabular}


Table 2. Economic parameters.

\begin{tabular}{|c|c|c|c|c|}
\hline \multirow{2}{*}{ Name } & \multicolumn{2}{|c|}{ Value } & \multirow{2}{*}{$\frac{\text { Min }}{{ }^{*} 1000 \text { riel }}$} & \multirow{2}{*}{$\frac{\text { Max }}{{ }^{*} 1000 \text { riel }}$} \\
\hline & *1000 riel & Dollars & & \\
\hline Price of rice straw(riel/kg ) & 0.106 & 0.03 & 0.025 & 0.333 \\
\hline Price of cut and carry natural grass (riel/kg ) & 0.210 & 0.05 & 0.033 & 0.483 \\
\hline Price for vaccination(riel/time) & 1.476 & 0.37 & 0 & 20 \\
\hline Price for de-worming (riel/head ) & 1.660 & 0.42 & 0 & 20 \\
\hline Price for treatment (riel/head ) & 7.676 & 1.92 & 0 & 70 \\
\hline Price of labor for take care cattle (riel/head/month ) & 20.910 & 5.23 & 0 & 50 \\
\hline Price selling ox (riel/head ) & 2629.248 & 657.31 & 600 & 6000 \\
\hline Price selling cow (riel/head ) & 2136.791 & 534.20 & 800 & 4500 \\
\hline Price selling calve (riel/head ) & 1597.108 & 399.28 & 500 & 4000 \\
\hline Salary off-farm job per year & 741.737 & 185.43 & 0 & 3960 \\
\hline Disposable income for livestock feeding & 1095.355 & 273.84 & 24.375 & 16243.75 \\
\hline Income from other agriculture production & 829.626 & 207.41 & 0 & 3918.44 \\
\hline
\end{tabular}

\section{Model Construction}

To clarify the relationship between the inter-related policies and small scale cattle production, cattle size and income consider optimum result range. We establish the following mathematical linear programming model to analyze off-farm job opportunity, suitable feed structure, and household income for cattle in rural Cambodia.

Objective function

$$
\begin{gathered}
\operatorname{Max} Y=P . \Delta Q+W_{o}\left(1-L_{f}\right) L-W_{f} L_{f} L-\sum \bar{Q} w_{i} \gamma_{i} m_{i}-\delta \bar{Q} P \\
\text { subject to } \gamma_{r s}=200 \\
\gamma_{f g}=136 \\
m_{r s}+m_{f g} \leq 12 \\
w_{f} L_{f} L+200 Q m_{r s} w_{r s}+136 Q m_{f g} w_{f g} \leq W_{0}\left(1-L_{f}\right) L+\text { other } \\
\text { di_income }=W_{0}\left(1-L_{f}\right) L+\text { other }
\end{gathered}
$$

From (5) and (6) we can get

$$
w_{f} L_{f} L+200 Q m_{r s} w_{r s}+136 Q m_{f g} w_{f g} \leq \text { di_income }
$$

Put $\alpha$ multiplier of (7) we can get

$$
\begin{gathered}
F=P Q+W_{o}\left(1-L_{f}\right) L-W_{f} L_{f} L-\delta Q P-\alpha\left(w_{f} L_{f} L+200 Q m_{r s} w_{r s}+136 Q m_{f g} w_{f g}-\text { di_income }\right) \\
\Rightarrow \frac{\partial F}{\partial Q}=P-\delta P-\alpha\left(200 m_{r s} w_{r s}+136 m_{f g} w_{f g}\right)=0 \\
\Rightarrow \frac{\partial F}{\partial L_{f}}=-W_{0} L-w_{f} L-\alpha\left(w_{f} L\right)=0
\end{gathered}
$$

From (9) we can get

$$
\alpha=-\left(1+\frac{w_{0}}{w_{f}}\right)
$$


By (10) it can be seen $\alpha \neq 0$, meet with Karush-kuhn-Tucker (KKT) condition, from (5) and (6) optimization algorithms can be established as methods for numerically solving the KKT system of equations.

$$
\begin{gathered}
L_{f}{ }^{*}=\frac{L W_{0}+\text { other }- \text { di_income }}{L W_{0}} \\
Q^{*}=\frac{W_{0}\left(1-L_{f}\right) L-w_{f} L_{f} L+o t h e r}{200 m_{r s} w_{r s}+136 m_{f g} w_{f g}}
\end{gathered}
$$

\section{Model Description}

The optimization model was basically exploring the income and potential income in rural household while the multiplicity of function fully concentrate on the ratio, cattle size, death rate, labor distribution. The multiplicity function explained in the above model includes the property value of cattle own by the farmer at the end of the year represented by $P . \Delta Q$; the wages accumulated from off-farm jobs represented by $W_{o}\left(1-L_{f}\right) L$; the cost of labor employed $W_{f} L_{f} L$; combined cost of feeding $\sum \bar{Q} w_{i} \gamma_{i} m_{i}$ and cattle death rate $\delta \bar{Q} P$. Further description is tabulated in the Table 3. Raising livestock especially cattle need more time extra maintenances and tending. Thus the model captures the additional cost of labor. Given the, the model also considers the death rate as a major factor to determining potential income of the farmers. The death of livestock is inevitable considering the system of free roaming and grazing practiced by majority of farmers in Cambodia. Livestock easily get infected by parasites, attacked by other wild animals and in most cases death of livestock as a result of the agrochemical used on farm.

\begin{tabular}{|c|c|}
\hline Acronyms & Description \\
\hline $\mathrm{Y}$ & Family Income or Net Income \\
\hline $\mathrm{P}$ & Cattle’s Price (unit 1000 riel/kg) \\
\hline$\Delta \mathrm{Q}$ & Changing $\Delta u t L$ number of cattle \\
\hline Q & Number of sale cattle in family \\
\hline $\mathrm{W}_{\mathrm{o}}$ & Annual salary from off-farmer job \\
\hline $\mathrm{L}_{\mathrm{f}}$ & Labour ratio for livestock \\
\hline $\mathrm{L}$ & Totally labour number household \\
\hline $\mathrm{W}_{\mathrm{f}}$ & Annual salary for cattle caring or take care cattle \\
\hline$\overline{\mathrm{Q}}$ & Average number of cattle stock in 2015 \\
\hline $\mathrm{W}_{\mathrm{rs}}$ & Price of rice straw ( unit 1000 riel $/ \mathrm{kg}$ ) \\
\hline $\mathrm{W}_{\mathrm{fg}}$ & Price of cut-and-carry natural fresh grass (unit 1000 riel/kg) \\
\hline$\gamma_{f g}$ & Cattle eating fresh grass feed per month per head \\
\hline$\gamma_{r s}$ & Cattle eating rice straw feed per month per head \\
\hline$m_{r s}$ & Month of rice straw as the feed of catte use \\
\hline$m_{f g}$ & Month of fresh grass feed as the feed of catte use \\
\hline$\delta$ & The ratio of cattle death \\
\hline$q_{r s}$ & Consumption of rice straw for cattle feed $(\mathrm{kg})$ \\
\hline$q_{f g}$ & Consumption of fresh grass for cattle feed $(\mathrm{kg})$ \\
\hline G & Gross cattle feed \\
\hline di_income & Diposable income for cattle feeding \\
\hline other & Other income from agriculture rice production \\
\hline
\end{tabular}

Table 3. Description of the acronyms used in the optimization algorithm. 
Cattle feed mainly consist of rice straw and natural grasses (cut-and-carry or free grazing). According to our survey, on average a head eat about $200 \mathrm{~kg}$ rice straw every month or about $136 \mathrm{~kg}$ of fresh grass per month. During scarcity of feed especially dry season and flooding season, farmer provide only rice straw to their cattle. The feeding for cattle is dependent on the seasonal variation, so the herd management is mostly carried out base on the seasons shown in the Figure 1.

According to cattle feed structure, May June, September, October, the feed value of rice straw and fresh grass get the real feed month. We denote month of rice straw (RS) and fresh grass (FG) as $m_{1}, m_{2}$ concisely the free grazing on field $(\mathrm{m} 1+\mathrm{m} 2 \leq 12)$. Another important factor for farmer to feed cattle size is disposable income because money is need to feed and labor hired. Pen et al (2010) mention that during the early wet season, cattle feed grazing constitute about $47 \%$ and 'cut-and-carry' $42 \%$ and concluded that cut-an-carry grass was important because it can be used during scarcity. Although rice straw and fresh grasses are the major feed components for local farmer but they lack of appropriate feed parameter for healthy cattle. On another hand, Stür and Horne (2009 and 2001) suggested that feeding the cattle with the native grasses and crop residues was becoming a constraint because as the number of animal increases, there is more pressure on the available land and thus scarcity of native grass sets in return causing low productivities.

\section{Results}

The result in Table 4 shows the number of cattle sold by households using the two sources of feed (rice straw and fresh grass) in conjunction with labor ratio to determining the potential household income in the six selected districts of Battambang province of Cambodia. The result also explains that there is certainly high potential to better income. Take for instance Banan, Ratanak Mondol and Thma Koul shows the highest optimal household income among the six districts they exhibit advantage because these district experienced lower death rate, lower healthcare cost and higher income attained from off-farms jobs. Other districts; Aek Phnum, Moung Ruessei and Sangkae showed an optimal income of 918 and 945 respectively on rice straw feed and on fresh grass 732 and 801 dollars respectively. The lowest among the district is seen in Aek Phnum (475 dollars), this is due to the fact that the productivity in the region is low in the region as a result of high disease infestation and death rate of cattle. During survey, some farmers complained on the effectiveness of vaccine, other complained poor veterinary serves. Moreover, the result not only explains the potential income but also the potentiality of the famers can increase (between $12.5 \%$ to $25 \%$ yearly) the size of their cattle head and maintain an optimal income.

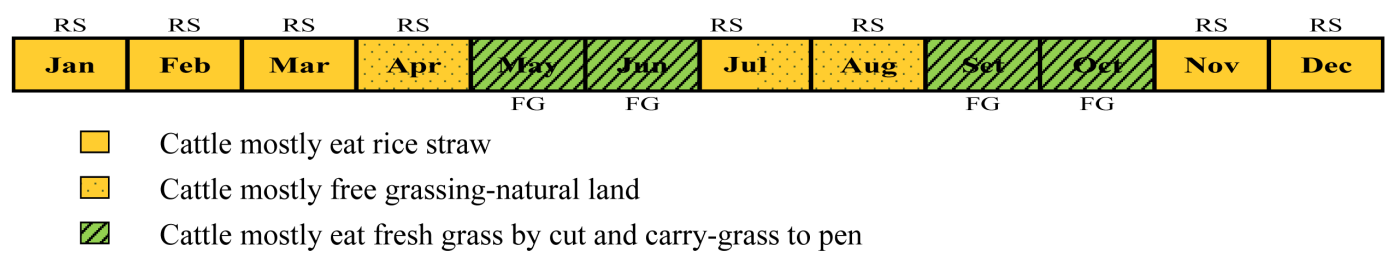

Figure 1. Feeding calendar.

Table 4. Optimum result.

\begin{tabular}{|c|c|c|c|c|c|c|c|c|}
\hline \multirow{2}{*}{$\mathrm{N}^{\circ}$} & \multirow{2}{*}{ District } & \multirow{2}{*}{$\mathrm{Q}_{1}$} & \multirow{2}{*}{$\mathrm{Q}_{2}$} & \multirow{2}{*}{$\mathrm{L}_{\mathrm{f}}$} & \multicolumn{2}{|c|}{$\mathrm{Y}_{1}$} & \multicolumn{2}{|c|}{$\mathrm{Y}_{2}$} \\
\hline & & & & & ( ${ }^{*} 1000$ riel) & Dollars & ( ${ }^{*} 1000$ riel) & Dollars \\
\hline 1 & Aek Phnum & 6 & 5 & 0.70 & 1901 & 475 & 1431 & 358 \\
\hline 2 & Banan & 9 & 5 & 0.54 & 5320 & 1330 & 4588 & 1147 \\
\hline 3 & Moung Ruessei & 8 & 10 & 0.65 & 3780 & 945 & 3203 & 801 \\
\hline 4 & Ratanak Mondol & 8 & 8 & 0.49 & 5673 & 1418 & 4735 & 1184 \\
\hline 5 & Sangkae & 9 & 6 & 0.54 & 3675 & 918 & 2928 & 732 \\
\hline \multirow[t]{2}{*}{6} & Thma Koul & 12 & 12 & 0.51 & 3940 & 985 & 3304 & 826 \\
\hline & Average & 9 & 8 & 0.58 & 3927 & 982 & 3257 & 814 \\
\hline
\end{tabular}




\section{Conclusions and Discussion}

The study uses Optimization model to determine the optimal potential income of cattle farmers in six districts of Battambang province of Cambodia and the result shows promising potentials in cattle production. Cattle husbandry in Cambodia is main source of family income in which commonly raising nearly all of household in rural area. Rice straw and fresh grass is an essential source of cattle feed. The more the use of rice straw the higher the income from the sale of cattle; contrary to this, the authors believe the nutritional value of fresh grass is greater than rice straw thus a healthy and fatty cattle can have more earnings. So the cost of these feed plays greater impact on the potential income of the farmers. Ceteris paribus the lower the cost feed the higher the earnings. The cost of rice straw is lower compared to fresh grass because in most times, the farmers employs labor to cut-and-carry to pen which in turn will cut down the earnings from the their revenue. Basically there are two form of labor force in the region, the household labor which can be cost free or employed labor which contributes to production cost. The labor force is almost evenly distributed between on farm and off-farm job.

This study suggests that the farmers could explore other source of feed via feed structure technology which identify and provide cost efficient parameters for cattle feed. Also to protect the environment from overgrazing and reduce the cost of buying fresh grass, the planting of forage for use and sell to other farmers can be of another good source of income. Moreover, to strengthen and sustain the cattle production, this study suggest that government should invest research and development (R \& D) and embark on rigorous extension services to help educate the famers and provide guidelines to the local farmers. Despite the declining cattle head seen over the years in the country, this study shows that there yet greater potential to retaining the previous glory of an increasing trend in cattle production given the appropriate government and private investment, extension services and establishment of feed industry.

\section{Acknowledgements}

This paper was supported by the CAAS Science and Technology Innovation Project (number: CAAS-ASTIP2016-AII), founded by Chinese Academy of Agricultural Sciences and Technology.

\section{References}

[1] FAOSTAT (2016) Food and Agricultural Organization of United Nation Website.

[2] Hun, S. (2014) National Strategic Development Plan, Royal Government of Cambodia.

[3] MacLean, M. (1998) Livestock in Cambodian Rice Farming Systems. Cambodia. International Livestock Research Institute, Australia Project (CIAP), Phnom Penh.

[4] MAFF (2013) Ministry of Agriculture, Forestry and Fisheries, Data Base Statistical.

[5] MAFF (2015) Ministry of Agriculture, Forestry and Fisheries, Agricultural Sector Strategic Development Plan 20142018, Kingdom of Cambodia.

[6] Pen, M., Savage, D., Stür, W., Lorn, S. and Seng, M. (2010) Cattle Feeding and Management Practices of SmallHolder Farmers in Kampong Cham Province, Cambodia. Inter. J. of Env. and Rur. Dev., 1, 132-138.

[7] Stür, W.W. and Horne, P.M. (1999) Forage Technology Development with Small-Holder Farmers, How to Best Varieties to Offer Farmers in Southeast Asia. ACIAR Monograph.

[8] Stür, W.W. and Horne, P.M. (2001) Developing Forage Technology with Small-Holder Farmers, How to Grow, Manage and Use. ACIAR Monograph. 